Estudios sobre armas antiguas, arte militar $\mathrm{y}$ vida cultural en oriente y occidente

XL (2020), pp. 93-112

ISSN: 0436-029X; eISSN: 1988-4168

https://doi.org/10.3989/gladius.2020.04

\title{
EL ASEDIO DE ALCALÁ LA VIEJA (1118) A TRAVÉS DE LOS PROYECTILES DE PIEDRA: UN ESTUDIO INTERDISCIPLINAR*
}

\author{
THE SIEGE OF ALCALÁ LA VIEJA (1118) THROUGH THE STONE PROJECTILES: \\ AN INTERDISCIPLINARY STUDY
}

\author{
POR \\ Mario Ramírez GaláN* y Rafael Montalvo Laguna**
}

\section{Resumen - ABstract}

El castillo de Alcalá la Vieja (Alcalá de Henares) ha sido objeto en estudio de numerosas investigaciones desde los años 80 pero siempre se había dejado olvidado el asedio que tuvo lugar en 1118. A raíz del descubrimiento de cuatro proyectiles de piedra en 2017, llevamos a cabo distintos trabajos para ampliar el conocimiento sobre este hecho histórico con el objetivo de rellenar ciertos vacíos existentes. Para esta tarea, optamos por llevar a cabo un estudio interdisciplinar, combinando datos arqueológicos e históricos con la aplicación de cálculos físicos y análisis espaciales. La unión de estas distintas ramas de investigación ha servido para solventar una serie de problemas documentales que se venían arrastrando desde hace mucho tiempo, lo cual no habría sido posible con un estudio histórico-arqueológico tradicional.

The castle of Alcalá la Vieja (Alcalá de Henares) has been the case study in numerous investigations since the eighties, but the siege — which took place in 1118 - has remained forgotten. Due to the discovery of four stone projectiles in 2017, we have carried out several works to widen the knowledge about this historical fact, and also to fill some existing gaps. For this task, we opted for proposing an interdisciplinary study: combining archaeological and historical data with physical calculations and spatial analyses. The amalgamation of different research areas has served to fix a series of documentary problems found in written sources; this would not have been possible following only a standard methodology based on historical and archaeological information.

\section{Palabras Clave - Keywords}

Alcalá la Vieja; arqueología; asedio; Edad Media; estudios interdisciplinares; proyectiles de piedra; siglo XII.

Alcalá la Vieja; archaeology; interdisciplinary studies; Middle Ages; siege; stone proyectiles; XII century.

\section{Cómo CITAR ESTE ARTículo / Citation}

Ramírez Galán, M. y Montalvo Laguna, R. (2020): «El asedio de Alcalá la Vieja (1118) a través de los proyectiles de piedra: un estudio interdisciplinar». Gladius, 40: 93-112. https://doi.org/10.3989/gladius.2020.04

\footnotetext{
${ }^{*}$ University of Portland, Department of History, Oregon, Estados Unidos, mario.ramirezgalan@gmail.com / OR-
} CID iD: http://orcid.org/0000-0001-7277-9242

${ }_{* *}^{*}$ Arqueólogo, Alcalá de Henares, r.montalvo.laguna@gmail.com / ORCID iD: http://orcid.org/0000-0003-19265212

Copyright (C) 2020 CSIC. Este es un artículo de acceso abierto distribuido bajo los términos de la licencia de uso y distribución Creative Commons Reconocimiento 4.0 Internacional (CC-BY 4.0) 


\section{INTRODUCCIÓN}

El recinto defensivo que conforma el yacimiento de Alcalá la Vieja se encuentra en el margen izquierdo del río Henares, a 644 metros de altitud, dentro del espacio denominado como Parque de los Cerros, un espacio natural protegido de titularidad pública al sureste de la ciudad de Alcalá de Henares (Madrid) catalogado como Monte de Utilidad Pública por la Consejería de Medio Ambiente de la Comunidad de Madrid en el año 2000. En el actual Plan General de Ordenación Urbana, el Parque de los Cerros se considera Área de Interés Arqueológico de Tipo A. La historia geológica de la zona está unida a la formación de la fosa del Tajo y desde un punto de vista geomorfológico, el margen izquierdo cuenta con fuertes escarpes y laderas de arcillas blandas y arenas miocénicas.

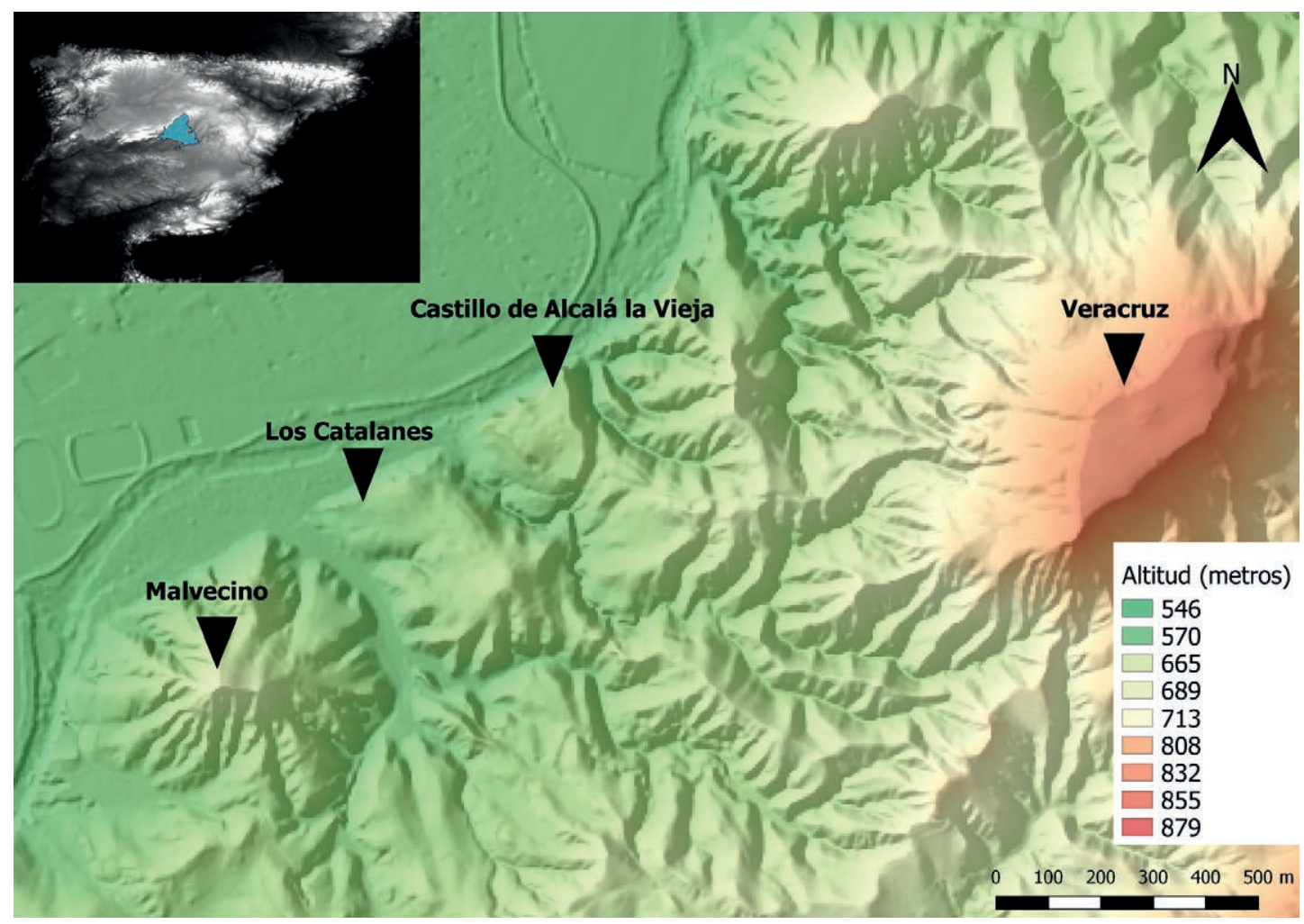

Figura 1. Localización de los emplazamientos cristianos y musulmán. Obra derivada de MDT5 2015 CC-BY scne.es. Fotografía: Mario Ramírez Galán.

Esta fortaleza se ubica en un enclave desde el que se dominaría la ruta de comunicación Toledo y Zaragoza, protegido por una orografía complicada y el río Henares. La población se asentaría en los arrabales que a fecha de hoy no han sido estudiados en profundidad.

El castillo de Alcalá la Vieja formaba parte del sistema defensivo de la marca media ante los ataques desde los territorios del Norte, controlados por los cristianos. Esta zona del territorio de al-Ándalus fue un espacio de conflicto militar debido a esas incursiones mencionadas y por este motivo se empieza un proceso de fortificación en la zona durante el siglo IX (Zorita, Medinaceli y Maqueda). En el siglo X, el sistema andalusí de defensa experimenta un impulso de la mano de Abderramán III (Herrera Casado, 1985: 11-12) y se formó una estructura 
defensiva de triángulos dobles, teniendo los vértices en Talamanca, Alcalá y Guadalajara, por un lado, y Talamanca, Madrid y Alcalá por otro. La distancia entre estas poblaciones era de una jornada de viaje, lo cual facilitaría tanto la comunicación como el desplazamiento, especialmente en momentos de conflicto. Estas fortificaciones se encontraban apoyadas por el sistema de atalayas levantado en las proximidades de los ríos Jarama y Henares. Estos puestos de observación y de control del territorio estaban localizados en Paracuellos, Rivas, Torrejón, Pezuela y Santorcaz. Durante el siglo XII el castillo de Alcalá la Vieja seguía bajo control árabe, formando parte de otro triángulo con las fortalezas de Oreja y Uclés (Echevarría Arsuaga, 1990: 635-636; Bru Castro y Schnell Quiertant, 2014: 94)

Desde que Juan Zozaya (1983) comenzara las intervenciones arqueológicas en los años 60, se vienen realizando diferentes campañas arqueológicas en el interior de la fortaleza de Alcalá la Vieja. Estos estudios han determinado una ocupación continuada desde época andalusí, pero sin poder concretar la fecha de construcción. A pesar de ello, se ha podido confirmar la ocupación de esta meseta elevada en épocas anteriores con estructuras de la prehistoria reciente y época carpetana. También se han localizado cerámicas romanas y tardorromanas en superficie.

Araceli Turina (1990: 189-194), quien excavó en los años 80 en esta fortaleza, determinó que la fortaleza sería construida a mediados del siglo IX. Existen otras afirmaciones basadas en que el topónimo Qal'at hace alusión a lugares con ocupación árabe, que serían de creación estatal, durante los primeros años de la conquista musulmana (Presas Vías et alii, 2009), siendo esta zona controlada por la familia bereber de los Banū Sālim.

El único nombre para la fortaleza que presenta garantías es el de Qal'at 'Abd al-Salam, el cual se cita en relación con sucesos acaecidos a principios del siglo XI. La consolidación de este topónimo reflejaría la configuración final de un recinto fortificado que hasta entonces habría sido un secundario hiṣn, cuya función sería la de refugio para un pequeño grupo (Castro Priego, 2011: 256-265).

La fortaleza pasó a manos cristianas tras la conquista en 1118, y en el 1129 el Rey Alfonso VII y doña Berenguela cedieron este territorio de Alcalá al arzobispo de Toledo, don Raimundo, pasando a ser parte de las posesiones de los posteriores arzobispos de Toledo (Fita Colomé, 1885: 336-338).

A tan solo 472 metros de distancia del enclave se localiza la base del cerro Malvecino, una elevación con forma cónica que jugó un papel determinante en el asedio de la fortaleza, tal y como lo refleja la documentación escrita. Se encuentra separado del castillo por un barranco y unas lomas que se elevan suavemente hasta alcanzar los 698 metros de altitud. Esta elevación cuenta con diferentes terrazas, algunas de ellas naturales, pero otras son obra de los trabajos de replantación del Parque de los Cerros. En su base y en el entorno se han documentado restos y estructuras tanto de época romana como medieval, según recoge la carta arqueológica de la Comunidad de Madrid en la que se hace referencia a la prospección realizada en 1957 por K. Raddatz. Esta información pudo ser confirmada por la prospección realizada por D. Fernández-Galiano (1976) donde se apreciaban estructuras de muros y restos de construcción medievales, así como restos cerámicos asociados a un contexto medieval. Desafortunadamente, estos hallazgos no se localizaron en la prospección llevada a cabo por S. Rascón Marqués y A. Méndez Madariaga en los años noventa. A lo largo de los años se han podido observar fragmentos de material cerámico en superficie en las inmediaciones del castillo y en las laderas del cerro Malvecino. 


\section{EL ASEDIO DE ALCALÁ LA VIEJA}

En la Edad Media, existían diferentes técnicas para asaltar y conquistar una plaza, las cuales se pueden agrupar en varios grupos en función de los métodos usados: a furto, por fuerça y el bloqueo o cerco (García Fitz, 1998: 217-242). El primero de estos métodos se basaba en un asalto por sorpresa, sin necesidad de emplear grandes contingentes de tropas sino grupos reducidos. Para que estos ataques tuvieran éxito era necesario la existencia de unas condiciones en particular, como momentos de escasa visibilidad para dificultar el control de los defensores, la presencia de poca vigilancia en dicho momento y lugar, y unidades especializadas. Todo este crearía el caldo de cultivo ideal para el asalto, pero su conjunción en un momento dado era muy complicada.

Los asaltos mediante la utilización de métodos de fuerza, tenían como objetivo una conquista rápida para reducir el coste de las pérdidas que ocasionaban este tipo de actividades bélicas. Además, un asedio de corta duración impedía que los sitiados pudiesen recibir ayuda del exterior

Como consecuencia de los problemas que podía presentar un ataque directo, en multitud de ocasiones se optaba por cercar o bloquear la fortaleza. Con esta fórmula se buscaba un aislamiento de la plaza del exterior, cortando todas las posibles vías de comunicación, avituallamiento y la llegada de ayuda desde otros lugares. No obstante, la selección de esta forma de conquista no significó que no se usasen alguno de los otros métodos, puesto que era común su utilización en momentos concretos con un objetivo particular. De este modo, el uso de maquinaria de asedio y el asalto tendría como objetivo minar la moral de los sitiados y conseguir desmoralizarlos.

Las descripciones sobre el asedio de Alcalá la vieja, provenientes de las fuentes escritas, se caracterizan por ser demasiado escuetas y confusas, prestando atención a otros elementos existentes durante el asedio más que al asalto en sí, como por ejemplo el milagro de la Veracruz. Esta falta de información, o la existencia de datos confusos, se puede deber a que las fuentes que mencionan este hecho histórico son secundarias. Como consecuencia de estos problemas, era necesaria la aplicación de un estudio que nos permitiese solventar estos inconvenientes y rellenar los vacíos documentales existentes. Para ello, optamos por un estudio interdisciplinar que nos aportase aquella información inexistente, bien por desconocimiento de los autores o bien por errores durante el proceso de transcripción. A pesar de ello, la consulta de documentación histórica era completamente necesaria, siendo el punto de partida para nuestra posterior propuesta.

La fuente escrita más cercana en el tiempo existente es el relato del arzobispo don Rodrigo Jiménez de Rada en su obra De rebus Hispaniae. Hace varias menciones a la toma de Alcalá, las cuales carecen de una explicación sobre el desarrollo del asedio, aunque nos deja varias referencias y datos que son de gran utilidad para el conocimiento de este hecho protagonizado por el arzobispo de Toledo don Bernardo de Sedirac: «Durante su reinado Bernardo, que a la sazón era el primado, conquistó Alcalá». En el capítulo sobre la toma de Alcalá y Valencia, relata que don Bernardo organizó el asedio del castillo de Alcalá «que era casi inexpugnable, y levantó otro castillo en una colina desde la que dominaba al primer castillo» (Jiménez de Rada, 1989: capítulo XXVIII). «Y víctimas al cabo del hambre, los habitantes del lugar escaparon por senderos ocultos», quedando bajo su tutela la fortaleza de Alcalá la Vieja.

Por su parte, Ambrosio de Morales (1793), en su obra Opúsculos castellanos: crónica general de España (siglo XVI), indica que don Bernardo, acompañado de su ejército, cercó la fortaleza. Además, levantó una bastida a modo de fortaleza en otro cerro cercano al castillo de Alcalá la Vieja desde el cual comenzó a asediar con los trabucos y otras máquinas de guerra la plaza enemiga. Dichas máquinas arrojaban grandes piedras para derribar los muros. Un dato muy interesante que proporciona Ambrosio de Morales es la alusión a la existencia de los res- 
tos de esa bastida o construcción militar en el cerro donde se despliega el ejército comandado por el arzobispo.

Como vemos, tanto Jiménez de Rada como Ambrosio de Morales hacen mención a la construcción de una estructura defensiva en una colina o cerro cercano para el control militar de la zona asediada. Hemos localizado diversas menciones que señalan al cerro Malvecino como el lugar donde se construye dicha fortificación temporal (Portilla y Esquivel, 1725: 148; Torres Balbás, 1959: 165-166; Palacios Ontalva, 2006: 40). Todas las fuentes escritas localizadas que hablan sobre el asedio afirman que el cerro Malvecino cumple la función de punto avanzado de observación. Desde dicho lugar las tropas cristianas vigilaban los movimientos de los pobladores de la fortaleza de Alcalá la Vieja (Calleja Carrasco, 1897: 30).

Portilla y Esquivel (1725: 148), Calleja Carrasco (1897: 30) y Torres Balbás (1959: 165166) recogen una referencia basada en el testimonio de Ambrosio de Morales en la que se asegura que el Malvecino fue el lugar donde se ubicaron las máquinas de guerra, y que era posible observar restos en el terreno de las trincheras que sirvieron para la instalación de los ingenios.

De todas las fuentes disponibles para el estudio del asedio de Alcalá la Vieja, Demetrio Calleja es quien aporta una mejor descripción del mismo. Según dicho autor, don Bernardo asedió y tomó la fortificación en el año 1118. Desde que el Rey Alfonso VI conquistase la villa de Alcalá en el 1086, la fortaleza de Alcalá la Vieja y sus pobladores resistieron treinta y dos años, gracias a que este lugar poseía unas defensas naturales muy potentes que lo convertían en prácticamente inexpugnable. A esto hay que añadir la ayuda prestada por las tropas musulmanas provenientes de poblaciones circundantes.

Don Bernardo de Sedirac organizó a su hueste y marchó hacia el castillo de Aldovea, donde se alojaron para descansar. Este enclave se encontraba situado en el actual término municipal de Torrejón de Ardoz. Tras esta parada, el ejército cristiano se desplazó por el margen izquierdo del río y fueron atravesando las distintas elevaciones existentes en la zona. El arzobispo y sus hombres ocuparon el cerro conocido como Malvecino, situando su puesto avanzado para controlar cualquier movimiento de los defensores, así como cortar las posibles líneas de comunicación y abastecimiento con poblaciones bajo control musulmán. En esta misma posición, y según las explicaciones aportadas por Calleja, el ejército cristiano desplegaría los trabucos para asediar la fortaleza musulmana. El arzobispo ordenó el levantamiento del campamento principal en la cima más elevada del entorno conocida como Veracruz, que actualmente recibe el nombre del cerro del Ecce Homo.

Durante el ataque cristiano, las tropas sitiadas defendían el castillo valientemente disparando proyectiles desde los muros para repeler el ataque, consiguiendo frenar las acometidas cristianas en numerosas ocasiones.

El tres de mayo fue una fecha clave para el ejército cristiano porque tras el discurso de don Bernardo para motivar a sus tropas, los soldados cristianos observaron sobre la cima del cerro Veracruz una cruz brillante. Este milagro envalentonó a los asaltantes que realizaron un nuevo ataque. Ante esta aparición, los defensores musulmanes reaccionaron de manera contraria, abandonando sus posiciones, cruzando el río Henares e incluso saltando desde los muros de la fortaleza al vacío (Calleja Carrasco, 1897: 17-18).

\section{TIPOLOGÍAS DE TREBUCHETS EN ÉPOCA MEDIEVAL}

El análisis de las fuentes escritas nos permitió observar cómo los distintos autores que hablaban sobre el asedio de Alcalá la Vieja, mencionaban de manera constante un mismo tipo de máquina de guerra medieval. Concretamente, nos referimos al término trabuco, pero a pesar 
de esta referencia era necesario intentar concretar la tipología de trabuco, puesto que durante la Edad Media existieron distintos tipos.

Al igual que ocurría con la información relativa al asedio proveniente de las fuentes documentales, las descripciones sobre la maquinaria bélica medieval son confusas y escuetas, dificultando una aproximación completa y en profundidad de los ingenios medievales. Autores de distintos países, recalcan este problema en las fuentes escritas, reflejando que no hablamos de un problema exclusivo de la documentación medieval hispana, ya que, por ejemplo, en Inglaterra se hace ilusión a ello (García Fitz, 2005: 223-224; García Fitz, 2011: 820; Hosler, 2015: 192-193)

En las fuentes medievales hispanas, la presencia de máquinas de guerra categorizadas dentro del grupo de destrucción (García Fitz, 2005: 235) es mencionada de una manera más constante que el resto de tipologías: aproximación y asalto. Este interés en este tipo de ingenios aporta una mayor cantidad de datos, pero siempre dentro de la escasez y la ambigüedad de los mismos.

Los problemas a los que se tienen que hacer frente a la hora de su estudio son principalmente dos: primero, la utilización de un mismo nombre para referirse a distintas máquinas de guerra; y segundo, dos términos distintos para referirse al mismo tipo de ingenio. Como se puede observar, ambos problemas no hacen más que dificultar el estudio de una parte muy específica de la historia bélica que se basa mayoritariamente en la documentación escrita, debido a la escasez de datos arqueológicos.

El término trebuchet, según Chevedden (2000: 99), se compone de dos partes: la primera de ellas es el prefijo tri (tres), y la segunda sería el término en latín bracchium (brazo). Literalmente, significaría máquina con tres brazos. Gracias a la existencia de miniaturas e iluminaciones medievales, es posible comprobar la explicación proporcionada por ese autor, así como ver la evolución de las máquinas.

Las fuentes medievales hispanas usan distintos términos para referirse a esta tipología de máquina perteneciente a la familia de los trabuquetes (García Fitz, 2005: 239-241). Es posible encontrar referencias a estos ingenios bajo el término mangana, el cual fue utilizado en la documentación referente al asedio de Almería del año 1147. Otro de los nombres existentes en las crónicas medievales es fundibula, el cual hace referencia a una máquina lanzadora de proyectiles de piedra mediante tracción humana. Junto con estos dos términos, es posible localizar referencias a las algarradas y a los trabuquetes, siendo el primero de ellos una versión más ligera, mientras que el segundo sería el modelo más potente, el cual se basaba en un sistema de palancas. La aparición de los trabuquetes tuvo lugar a principios del siglo XIII.

Basándonos en la información existente, es posible diferenciar la existencia de varios modelos para los ingenios de esta categoría: de tracción, híbrido y de contrapeso fijo. Dentro de esta clasificación existe cierta controversia porque hay dos grupos marcadamente diferenciados: aquellos que defienden la existencia de una máquina intermedia entre la de tracción y la de contrapeso fijo; y aquellos que no comparten esa división, alegando que el mal llamado híbrido fue simplemente un paso previo y que la incorporación del pequeño contrapeso fue meramente un proceso evolutivo, pero que no se podía entender como un modelo distinto (Basista, 2007). Nosotros hemos optado por usar la primera clasificación, puesto que simplifica la categorización de las distintas modalidades a la hora de explicar su composición y funcionamiento.

El trabuco de tracción fue creado entre el siglo V y III a. C. en China (Chevedden et alii, 1995: 66-67; Chevedden, 2000: 73; Tsurtsumia, 2015: 178) y su funcionamiento consistía en un grupo de hombres tirando de cuerdas para lanzar los proyectiles (Chevedden et alii, 1995: $68)$. 


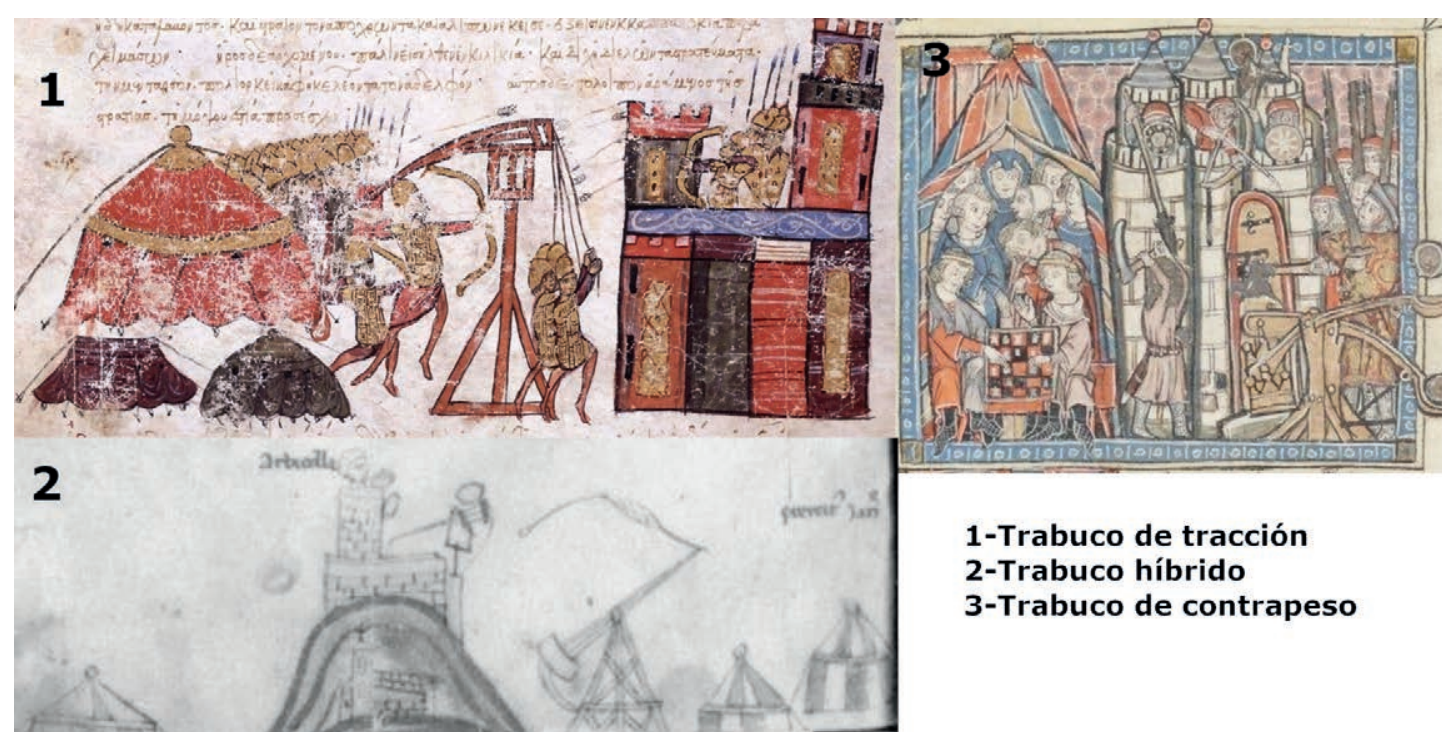

Figura 2. Tipos de trabuco. 1) Historia Scylitzes, folio 151r. «Biblioteca Nacional de España» 2) Annales de Genes, Lat. 10136, folio 141v. «Sourcegallica.bnf.fr / Bibliothè quenationale de France» 3 ) Folio 94v. Histoire de la guerra sainte [par Guillaume, de Tyr] traduction et continuation. Date: 1201-1300. «Source gallica.bnf.fr / Bibliothèque nationale de France». Fotografía: montaje realizado por Mario Ramírez Galán.

La segunda categoría es el trabuco de tipo híbrido, que empezó a reemplazar al modelo anterior a comienzos del siglo VIII y se expandió durante el siglo IX por Oriente Medio, el ámbito mediterráneo y Europa occidental (Chevedden, 2000: 74; Chevedden et alii, 2000: 442443). No obstante, otros autores defienden la convivencia de ambas máquinas tras la aparición del modelo híbrido. Esta versión combinaba rasgos del trabuco de tracción y del de contrapeso fijo, debido a que el contrapeso era demasiado pequeño para crear la fuerza necesaria para lanzar la roca y necesitaban un sistema capaz de incrementarla (Chevedden et alii, 2000: 456; Sáez Abad, 2007: 103). Para ese propósito, siguieron usando cuerdas tiradas por hombres. Además, y según Chevedden et alii (2000: 456), el uso del contrapeso era «to balance the beam forward of the axle at the moment of discharge»».

Finalmente, el último de los modelos era el llamado trabuco de contrapeso fijo. Este tipo apareció en el siglo XII, pero los autores (Tarver, 1995: 146, 167; Saimre, 2006: 64; Tsurtsumia, 2015: 180) no concretan una fecha y dan distintos momentos para su aparición. Uno de ellos (Chevedden, 2000: 76) piensa que su origen pudo ser al final del siglo XI.

Básicamente, la forma en la que esta máquina funcionaba era la misma que los otros modelos, con la salvedad de la sustitución de la fuerza humana por un pesado contrapeso que aplicaba la fuerza necesaria para disparar el proyectil (Gillmor, 1981: 1; Tarver, 1995: 167; Chevedden, 1998: 179; Chevedden et alii, 2000: 435; Saimre, 2006: 62; Tsurtsumia 2015: 180). Con esta mejora, el rango de tiro era siempre el mismo, puesto que la fuerza ejercida era la misma como consecuencia de una masa invariable. Estos contrapesos eran rellenados con arena, piedras u otros materiales (Sáez Abad, 2007: 103-104). Una de las consecuencias de esta mejora fue el incremento de la potencia del trebuchet.

Según diferentes autores, quienes se basaron en un tratado militar escrito por Salah al-Din, el trabuco de tracción podía disparar un proyectil a una distancia de entre 80 y 120 metros. Varios investigadores aportan datos provenientes de un tratado chino de 1044, en donde la 
información referente al alcance presenta valores similares con la anterior fuente mencionada (Chevedden, 2000: 74; Chevedden et alii, 2000: 443).

Para conocer la distancia tuvimos en cuenta estudios experimentales actuales, los cuales explicaban que el trabuco accionado mediante fuerza humana podía disparar un proyectil de 60 kilos a una distancia entre 85-133 metros (Sáez Abad, 2007: 100). Desafortunadamente, no había datos sobre el alcance del trabuco híbrido y solamente datos sobre el peso de los proyectiles. A pesar de ello, la evolución de la máquina de asedio previa supondría una mejora para el alcance y la precisión de la misma.

La mejora en la maquinaria de guerra medieval fue la creación del contrapeso fijo. Estudios recientes, e investigaciones experimentales, han podido mostrar datos muy valiosos sobre ello, los cuales son necesarios para conocer las características de este tipo de ingenio medieval. El origen de estos experimentos tuvo lugar en el siglo XIX cuando Napoleón III ordenó la construcción de varias de estas máquinas. La persona a cargo fue Ildefonso Favé y el trebuchet solo pudo disparar cuatro veces, obteniendo los resultados recogidos en la tabla 1 (Saimre, 2006: 74; Sáez Abad, 2007: 204).

Tabla 1. Rango de disparo. Autor: Mario Ramírez Galán.

\begin{tabular}{|c|c|}
\hline Proyectil & Distancia \\
\hline Bola de cañón, $10.88 \mathrm{~kg}$ & $175 \mathrm{~m}$ \\
\hline Proyectil, diámetro $22 \mathrm{~cm}$ & $472 \mathrm{~m}$ \\
\hline Proyectil, diámetro $27 \mathrm{~cm}$ & $120 \mathrm{~m}$ \\
\hline Proyectil, diámetro $32 \mathrm{~cm}$ & $120 \mathrm{~m}$ \\
\hline
\end{tabular}

Por otro lado, Payne-Gallwey (Saimre, 2006: 66), a comienzos del siglo XX, llegó a la conclusión que el trabuco más poderoso podía disparar un proyectil de 140 kilos a 300 metros con un contrapeso de 9000 kilos. Por su parte, Peter Vemming Hansen, fabricó varios trabucos para conocer el alcance de disparo, llegando a lanzar un proyectil de 15 kilos a 168 metros con un contrapeso de 2 toneladas (Saimre, 2006: 75). Sin embargo, Hansen, basándose en cálculos físicos, concluyó que esta máquina podría haber disparado hasta 490 metros.

Los investigadores han seguido trabajando acerca del mecanismo de estas armas de asedio, obteniendo diferentes valores como resultado de la utilización de contrapesos y proyectiles con distintas masas. Chevedden (2000: 72) señala que el trebuchet representado en la obra de Villard de Honnecourt era de contrapeso fijo y los investigadores indicaban que la caja podría haber tenido una masa de aproximadamente 30.000 kilos. Con este valor y las correspondientes modificaciones, llevaron a cabo cálculos para obtener el alcance máximo.

Tabla 2. Rango de disparo según el peso de la caja y el proyectil. Autor: Mario Ramírez Galán.

\begin{tabular}{|c|c|c|}
\hline Peso de la caja & Peso del proyectil & Distancia \\
\hline $30 \mathrm{t}$ & $100 \mathrm{~kg}$ & $400 \mathrm{~m}$ o más \\
\hline $30 \mathrm{t}$ & $250 \mathrm{~kg}$ & $160 \mathrm{~m}$ o más \\
\hline $15 \mathrm{t}$ & $100 \mathrm{~kg}$ & $217 \mathrm{~m}$ \\
\hline $15 \mathrm{t}$ & $60 \mathrm{~kg}$ & $365 \mathrm{~m}$ \\
\hline
\end{tabular}


Las fuentes históricas referentes al objeto de nuestro estudio coinciden en el tipo de máquinas, trabuco, así como en su localización en el cerro de Malvecino, pero era necesario concretar la tipología de trebuchet y corroborar o refutar la supuesta zona de despliegue de los ingenios. Para ello, nos basamos en dos factores provenientes de estudios previos, como son la fecha y el alcance.

La batalla y asedio de Alcalá la Vieja tuvo lugar en 1118 y las máquinas de asedio usadas para atacar el castillo musulmán tuvieron que ser creadas con anterioridad a su utilización. Según la cronología aportada por varios autores, el uso del trabuco sin fuerza humana está completamente descartado porque fue creado con posterioridad a nuestro caso de estudio. La mayoría de ellos creen que su origen tuvo lugar durante el siglo XII y solo Chevedden, lo sitúa a finales del XI. Por este motivo, Morales y el resto de autores de las fuentes históricas debieron estar refiriéndose al trabuco de tracción o al híbrido, e incluso a ambos.

Basándonos en la información cronológica, pensamos que el modelo usado, y que se adaptaría mejor al objetivo de romper las defensas enemigas, por el ejército de don Bernardo de Sedirac podría haber sido el de tipo híbrido. Esta nueva versión era más poderosa que su predecesora, habida cuenta que era capaz de lanzar proyectiles más pesados a mayor distancia, siendo su capacidad destructiva mayor. Sin embargo, es complicado especificar (García Fitz, 2005: 235-236) la tipología porque los documentos escritos no son muy claros en este aspecto e incluso se pudieron combinar trabucos híbridos para atacar las defensas de la fortaleza y trabucos de tracción para causar bajas contra los defensores situados en las almenas y torres.

En la península ibérica, entre 1050 y 1150 , la presencia de máquinas de guerra de este tipo era común en los asedios, lo cual nos permite conectar su uso con el castillo de Alcalá la Vieja y corroborar el uso de dicha máquina. Por ejemplo, en 1192, el Cid Campeador (García Fitz, 2005: 236) usó un ingenio para disparar proyectiles contra la ciudad de Valencia. Durante el asedio de Toledo (1109), los almorávides usaron el mismo tipo de máquina (Sáez Abad, 2007: 159-160, 163) y también podemos observar la misma tipología de maquinaria bélica en Ibiza, Mallorca (1113-1115) y Coria (1142).

El último factor que tuvimos en consideración para comprobar la información sobre el despliegue de las máquinas de guerra en Malvecino fue la distancia comprendida entre dicha posición y la fortaleza.

Previamente, medimos la separación desde dos puntos en el cerro de Malvecino para tener la distancia máxima y mínima desde dicho lugar. Los resultados fueron, respectivamente, 709 m y 472 m desde la cima y el pie de Malvecino, a la entrada principal de Alcalá la Vieja. Dichas distancias entre estos puntos era enorme y ninguna de las máquinas de asedio habría sido capaz de disparar a esa distancia. Por lo tanto, y basándonos estrictamente en los cálculos realizados por los investigadores a través de la arqueología experimental mostrados anteriormente, vimos que el uso de trabucos en Malvecino no sería factible. Únicamente el de contrapeso fijo, según los datos facilitados (Chevedden, 2000), podrían haber disparado desde allí.

A la hora de evaluar el despliegue de las máquinas de guerra, también tuvimos presentes otro factor que no se encontraba recogido en las fuentes escritas, como era la orografía del terreno. La zona del cerro de Malvecino se caracteriza por su irregularidad y su difícil acceso. Estamos hablando de una elevación protegida por defensas naturales, barrancos, precipicios, fuertes pendientes, etc., en tres de sus cuatro lados, lo que le hace una gran posición para establecer un puesto avanzado. A pesar de esos aspectos positivos, el lugar carece de una superficie óptima para desplegar máquinas de guerra, incluso en el supuesto que se encontrase a una distancia factible para asediar la fortaleza de Alcalá la Vieja. Malvecino únicamente cuenta con dos áreas relativamente planas, una en la cima y otra en la loma orientada al este, las cuales poseen una pronunciada inclinación que impediría un disparo correcto debido a la inestabili- 
dad que se produciría durante el lanzamiento, así como a la angulación que se formaría entre el brazo y la pendiente.

Nosotros pensamos que en dicha zona sí fue factible la construcción del mencionado castillo temporal cristiano y que permitiría un despliegue de tropas y el levantamiento de tiendas, pero no sería posible la colocación de los trabucos por lo anteriormente mencionado.

\section{RESTOS MATERIALES PARA EL ESTUDIO DEL ASEDIO MEDIEVAL: LOS PROYECTI- LES Y EL CASO DE ALCALÁ LA VIEJA}

En numerosas ocasiones, cuando la documentación escrita no es adecuada para el conocimiento de un hecho histórico, el uso de los datos provenientes de trabajos arqueológicos aportan luz a las distintas investigaciones, siendo este nuestro caso. Dado que las fuentes que hablan sobre el asedio nos facilitan una información breve y en muchas veces confusa, acudimos a los datos arqueológicos asociados con este hecho.

Los trabajos arqueológicos llevados a cabo hasta la fecha en la zona de estudio, se han centrado en el análisis de la fortaleza de Alcalá la Vieja ${ }^{1}$ con la intención de determinar las distintas fases de ocupación y construcción (López Marcos et alii, 2011; 2013). Esto se contrapone con la falta de investigación acerca del asedio que sufrió el lugar en 1118 y la posterior toma por parte de las tropas cristianas comandadas por Bernardo de Sedirac.

El análisis de los campos de batalla, término donde se engloba el concepto asedio, es una de las ramas de la arqueología más recientes, mucho más si cabe en nuestro país, pero afortunadamente cada día el interés aumenta y los trabajos sobre este campo de estudio proliferan.

Uno de los principales problemas que nos encontramos cuando decidimos investigar estos yacimientos, los cuales son efímeros en comparación con otros, es la escasez de materiales (Ramírez Galán, 2016; 2017). Hablamos de lugares donde después del conflicto, el cual tienen una duración limitada en el tiempo, se llevaba a cabo una recogida de gran parte del armamento debido al intento de reutilización o a la obtención de botín. Si a esto le unimos la actividad de furtivos, el volumen de restos arqueológicos que podemos encontrar se reduce considerablemente. Además, debemos añadir un factor adicional que dificulta la investigación de los asedios, y más concretamente el estudio de las máquinas de guerra, nos estamos refiriendo al tipo de material empleado para su fabricación. Las máquinas de guerra dejan muy pocas trazas arqueológicas, por no decir que son prácticamente inexistentes. Esto es debido a que son construidas mediante la utilización de materiales perecederos, madera, que dificultan considerablemente su conservación. Debido a ello, los únicos restos asociados que podríamos hallar en este tipo de yacimientos serían aquellos fabricados con materia prima duradera, como la piedra.

La existencia de proyectiles de roca asociados a varios asedios medievales, ha sido constatada en varios yacimientos de Oriente Medio, los cuales están asociados a la presencia de ejércitos cruzados en dicho lugar. A través de su localización, los distintos autores intentaron situar las zonas con mayor potencialidad para haber albergado las máquinas de guerra.

Kate Raphael y Yotam Tepper estudiaron los restos materiales asociados al asedio de Arsuf (Israel) para localizar el despliegue de los trebuchets. Este yacimiento, tal y como indican ambos investigadores (Raphael y Tepper, 2005: 86), es un caso excepcional en la región por la gran cantidad de restos arqueológicos, proyectiles de piedra y puntas de flecha, pertenecientes al ataque, lo cual permitió cruzar información con las fuentes escritas de la época. De entre

\footnotetext{
1 Presas Vías, M., Serrano Herrero, E. y Torra Pérez, M. (2009): Memoria de las excavaciones arqueológicas realizadas en el yacimiento de Alcalá La Vieja (Alcalá de Henares, Madrid).
} 
ambas tipologías de restos, nosotros nos centramos en las rocas lanzadas para poder establecer paralelos con el caso de Alcalá la Vieja.

Un total de 2747 proyectiles de piedra fueron localizadas en la zona del asedio de Arsuf, de las cuales 800 fueron pesadas y medidas. Basándose en la tipología, establecieron diferencias de tamaño entre las rocas halladas al norte de la puerta de la fortaleza y las que se encontraron dentro de los muros de la ciudadela. Las primeras presentaban un mayor diámetro y un peso superior al segundo grupo. Esto indica la existencia de dos tipos de trabuco, ya que sería necesario un trebuchet mayor para disparar piedras de mayores dimensiones.

El material utilizado para fabricar los proyectiles fue roca caliza y presentan grandes diferencias en cuanto a peso y diámetro, teniendo valores que oscilan entre $1 \mathrm{~kg}$ para las más livianas y $78 \mathrm{~kg}$ para la más pesada. Es destacable mencionar, que de entre todos los proyectiles analizados, únicamente un pequeño porcentaje presentaba una forma casi completamente esférica e incluso algunas estaban prácticamente sin trabajar. Esto nos indica la necesidad de una fabricación rápida, dotándolas solo de una rudimentaria esfericidad para facilitar su lanzamiento y disminuir el rozamiento con el aire. En lo que respecta a las dimensiones de los proyectiles, poseían un diámetro entre los 20 y los $40 \mathrm{~cm}$.
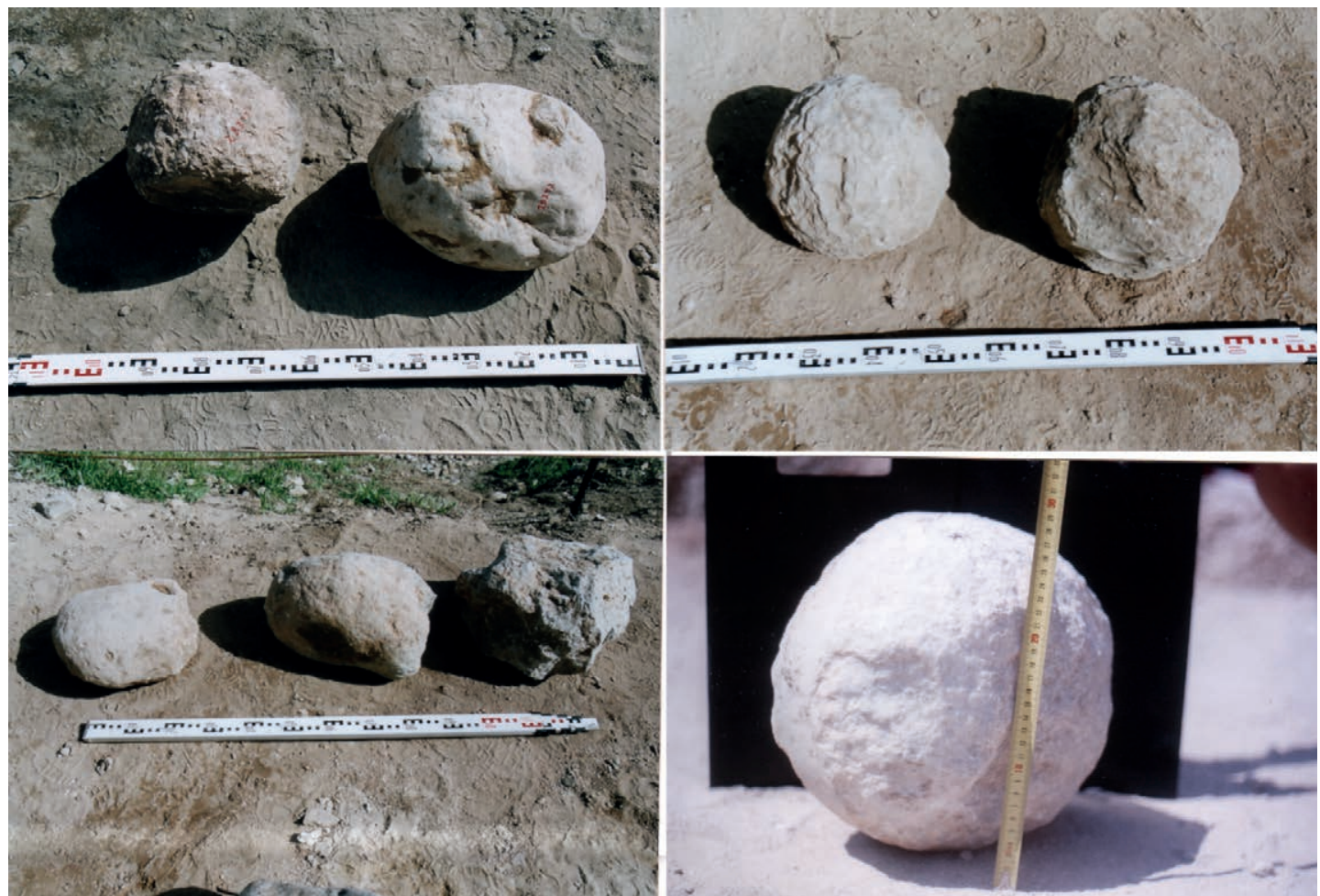

Figura 3. Proyectiles localizados en el yacimiento de Arsuf. Fotografías: cortesía de Kate Raphael y Yotam Tepper.

El otro yacimiento que ha permitido constatar la existencia de materiales pertenecientes a un contexto de asedio ha sido el castillo cruzado de Montfort (Israel). Los trabajos arqueológicos en dicha fortaleza (Boas, 2017a: 49-50; Boas, 2017b: 197-199; Fulton, 2019: 702-704) se han venido realizando desde comienzos del siglo XX cuando el Museo Metropolitano de Arte de Nueva York y Bashford Dean iniciaron una serie de excavaciones en 1926. Durante dichas 
excavaciones, localizaron en la zona residencial de castillo un grupo proyectiles de roca asociados a maquinaria de guerra medieval y al asedio sufrido por la fortaleza en 1271. El número total de los mismos era de 56.

Los diámetros de las rocas presentaban un rango que oscilaba entre los 25 y los 43 centímetros, presentando unas dimensiones bastante similares a las que poseían los proyectiles provenientes del asedio de Arsuf. Dos de ellas fueron enviadas a Estados Unidos para ser analizadas en detalle en el museo, las cuales fueron pesadas y medidas. Los valores obtenidos tras el pesaje y medición fueron $66 \mathrm{~kg}$ y diámetros de 33 y $35 \mathrm{~cm}$.

Casi un siglo después, en 2012 y 2017, se hallaron nuevos restos de proyectiles en sendas excavaciones arqueológicas en la fortaleza de Montfort. En la primera de ellas, la roca presentaba un tamaño menor a las anteriormente localizadas y un peso de $32,2 \mathrm{~kg}$. En 2017, un nuevo proyectil fue descubierto, el cual no estaba completo, conservándose la mitad del mismo. A pesar de ello, tenía un peso considerable, puesto que estamos hablando de una masa de $51 \mathrm{~kg}$.

$\mathrm{Al}$ igual que los materiales encontrados en Arsuf, los proyectiles de Montfort fueron fabricados usando caliza local y poseen cierta esfericidad pero con claros signos de tosquedad, pudiendo deberse a una fabricación rápida o bien a la falta de preparación de las personas que se encargaban de dicho trabajo.

La importancia de estos yacimientos es doble: en primer lugar, porque nos muestra la existencia de materiales arqueológicos asociados a máquinas de asedio medievales, siendo esto un bien escaso; y en segundo lugar, porque nos sirve como elemento comparativo a la hora de analizar tanto el asedio de Alcalá la Vieja, como los materiales localizados en nuestra zona de trabajo.

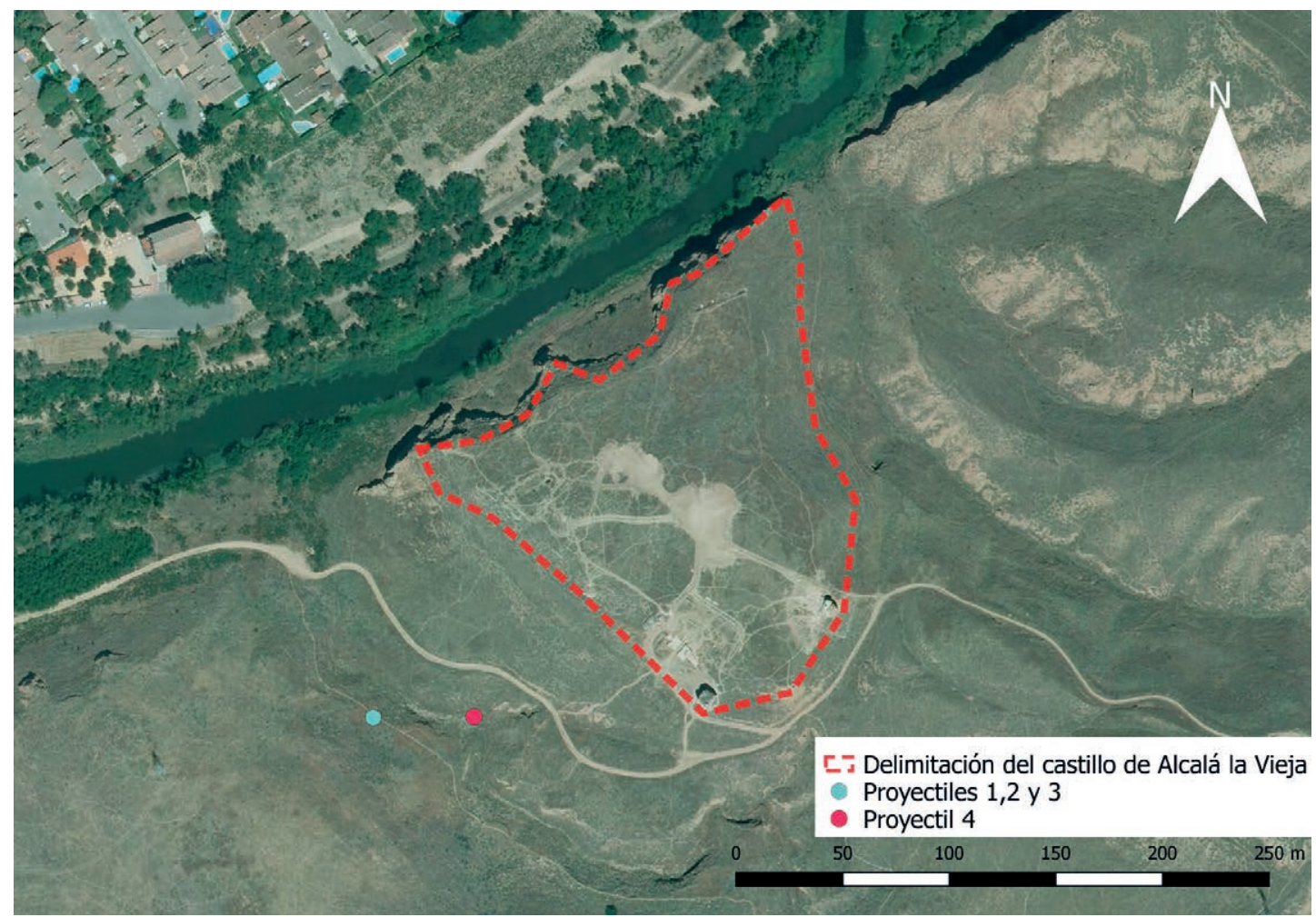

Figura 4. Ubicación de los proyectiles de Alcalá la Vieja. Obra derivada de OrtoPNOA 2014 CC-BY scne.es. Fotografía: Mario Ramírez Galán. 
En el año 2017 (Ramírez Galán y Montalvo Laguna, 2018; Ramírez Galán, Montalvo Laguna y Benítez Galán, 2019) se produjo el hallazgo casual en el entorno de la fortaleza musulmana de Alcalá de Henares de cuatro proyectiles de piedra. Dichos materiales fueron depositados en el Museo Arqueológico Regional de la Comunidad de Madrid, lugar donde pudimos estudiarlos. Llevamos a cabo trabajos de pesaje y medición para poder categorizar y comparar estos restos arqueológicos con los localizados en otros yacimientos de la misma tipología. Los resultados presentaban unas dimensiones bastante similares entre todos ellos, con la excepción del bolaño número 3, el cual tenía un diámetro algo más reducido. Los diámetros oscilaban entre los 28 y los $35 \mathrm{~cm}$. En lo que se refiere a la masa, los valores mostraban una mayor diferencia, yendo desde los $32,8 \mathrm{~kg}$ del proyectil más liviano a los $58,6 \mathrm{~kg}$ del más pesado.

En referencia a la forma y al material, decir que todos ellos presentan una forma relativamente esférica, siendo más apreciable en algún caso concreto, como por ejemplo el proyectil

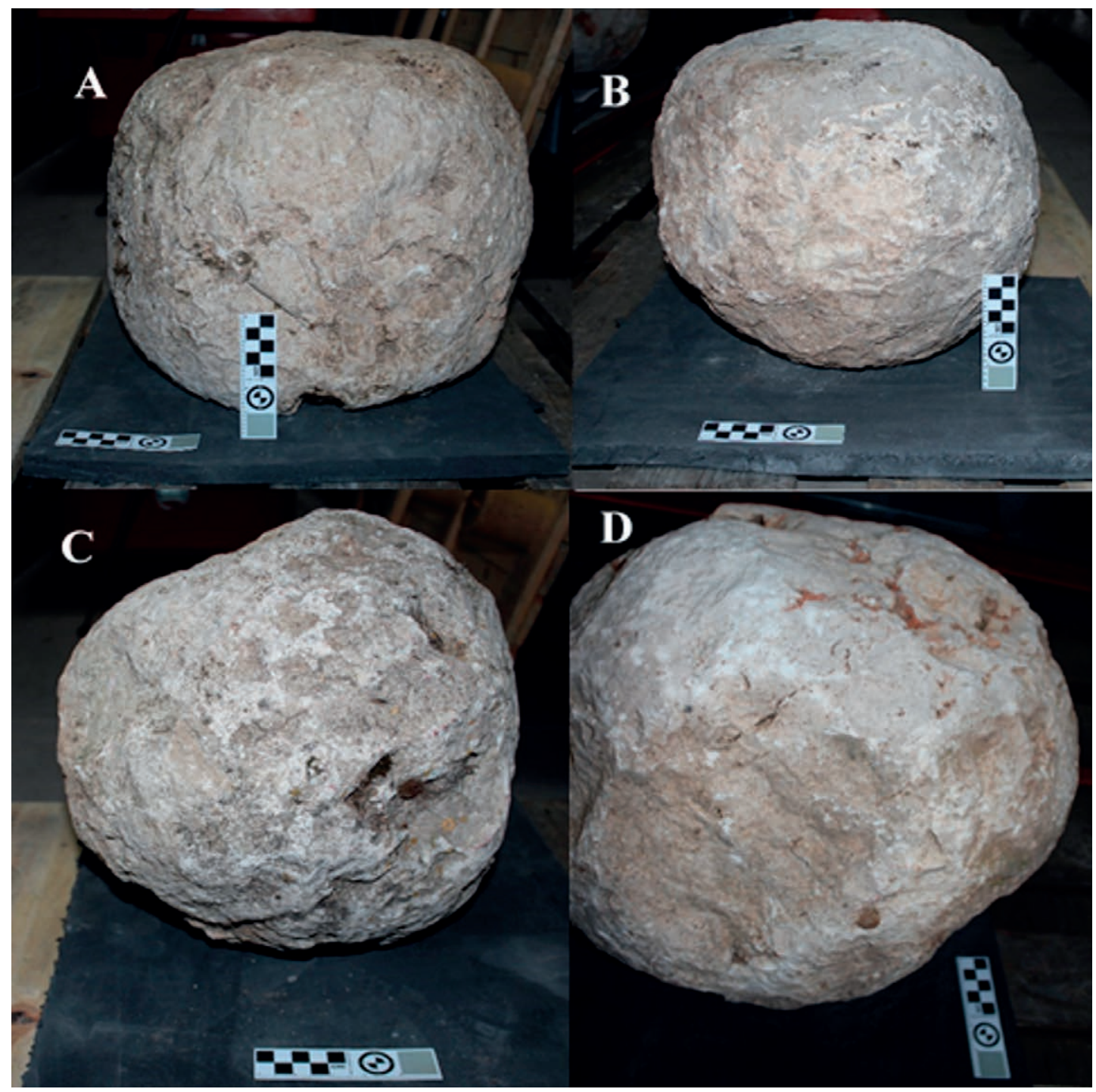

Figura 5. Proyectiles localizados en las inmediaciones de Alcalá la Vieja. Fotografía: Rafael Montalvo Laguna. 
2. En contraposición tenemos el proyectil número 3, que es el que posee una superficie más irregular de los cuatro. Se pueden ver varias zonas poco trabajadas que podría deberse a un tallado muy leve o incluso al estado del material. Los procesos erosivos también juegan un papel importante en la conservación de estos hallazgos y sería necesario valorar la posibilidad de una fractura del bolaño 4 en algún momento del tiempo, e incluso durante el asedio.

En cuanto a la materia prima utilizada, decir que los cuatro proyectiles fueron realizados en piedra caliza, al igual que los localizados tanto en Arsuf como en el castillo de Montfort.

Tras el estudio de estos hallazgos en las inmediaciones del castillo y su comparación con otros casos de estudio, pudimos establecer una serie de paralelos para estudiar los asedios de época medieval a través de los restos arqueológicos. Este análisis nos permite concretar que a pesar de las diferencias existentes de dimensiones y peso, parece posible establecer ciertos rangos para diámetro y masa, puesto que los proyectiles de Alcalá la Vieja coincidían, o al menos se encontraban dentro, con los valores calculados para los bolaños de Arsuf y Montfort. La misma situación la podemos encontrar con el material, porque en los tres yacimientos la materia usada para fabricarlos fue la caliza y estamos hablando de lugares con distinta localización geográfica. La utilización de la misma materia prima permite establecer un claro patrón entre los tres yacimientos, lo cual aporta una información muy valiosa para el entendimiento de la selección de materiales en los asedios de época medieval.

Estos datos parecen indicar la posible existencia de unas pautas preestablecidas o una formación previa a la hora de fabricar proyectiles de piedra durante la Edad Media, lo que podría interpretarse como una estandarización del procedimiento de fabricación pero sin olvidar ciertos factores que influirían en el producto final, como son la existencia de la materia, la calidad de la misma y la tensión que se experimenta durante un conflicto armado.

A pesar de la importancia de esta información, uno de estos elementos posee más interés para nosotros a la hora de entender aún más el asedio que tuvo lugar en tierras complutenses en el siglo XII y corroborar o corregir las fuentes documentales que hablan sobre dicho acontecimiento. Nos estamos refiriendo al peso de los proyectiles.

Gracias a los estudios interdisciplinares en arqueología, es posible aportar nuevos enfoques para el conocimiento de ciertos aspectos de los hechos históricos, los cuales no sería posible abordar sin la ayuda de otros campos de investigación. Para nuestra investigación hemos acudido a cálculos físicos con el objetivo de obtener los teóricos alcances máximo y mínimo de cada uno de los bolaños, siendo su masa completamente necesaria para su obtención. El conocimiento de las distancias para cada proyectil permitiría conocer el teórico alcance de los trebuchets utilizados por los hombres de Bernardo de Sedirac.

Dada la temática de la revista, explicaremos someramente en que consistieron dichos cálculos y como fueron utilizados para la obtención del rango de disparo, así como la importancia de esos valores.

A lo largo de este trabajo, la mención de la pobreza en las fuentes documentales ha sido una constante, tanto cuando hablábamos del caso concreto de Alcalá la Vieja como cuando nos referíamos al estudio de las máquinas de asedio medievales. Esta falta de datos, o de fiabilidad de los mismos, supuso un problema a la hora de llevar a cabo los cálculos físicos porque carecíamos de toda la información necesaria para obtener los alcances. En nuestro trabajo, y basándonos en las fuentes, propusimos la posibilidad del uso del trabuco híbrido durante el asedio pero en los documentos consultados no se hacía referencia a los siguientes elementos que necesitábamos:

- Número de hombres.

- Fuerza media de cada hombre. 


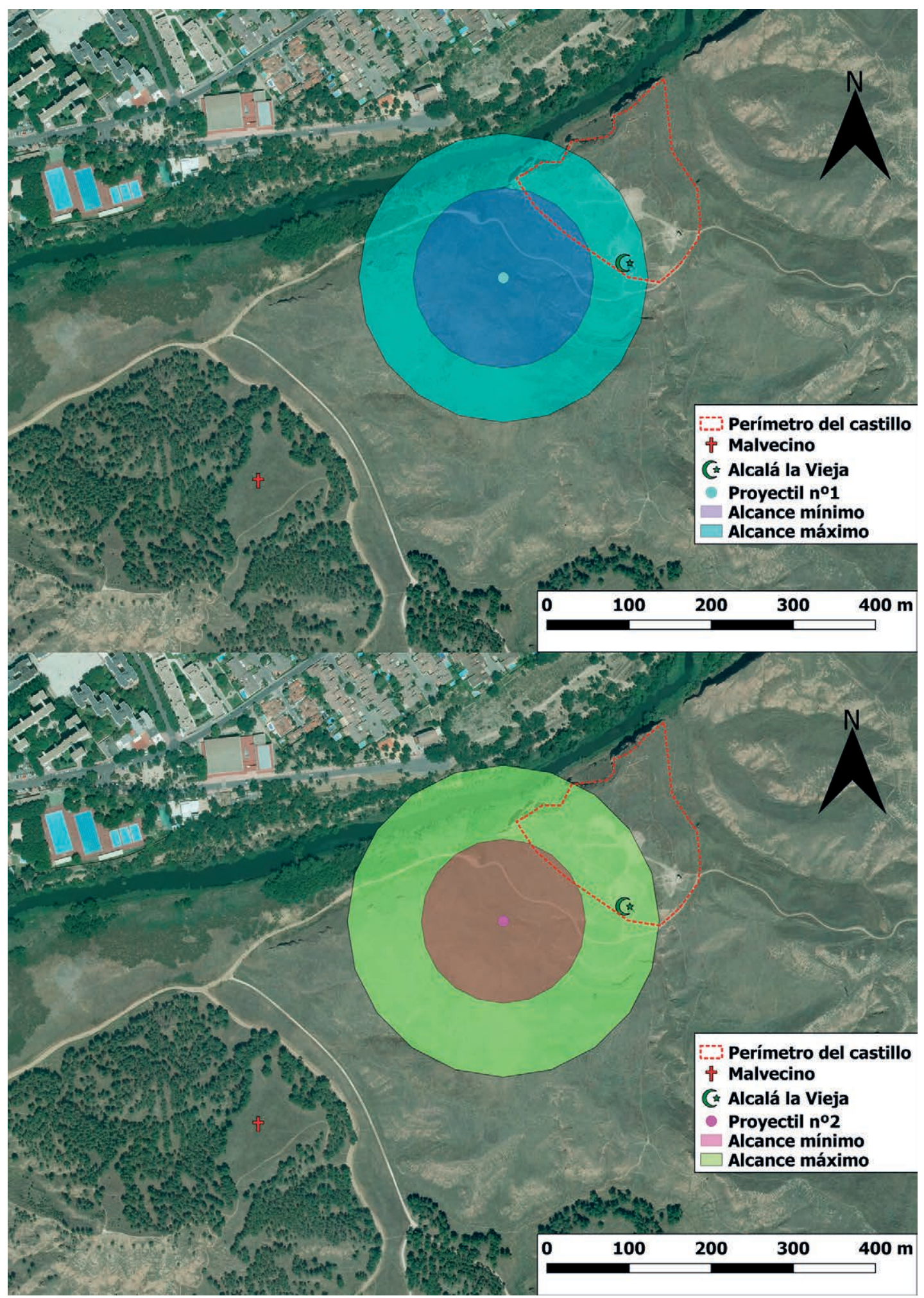

Figura 6. Alcance máximo y mínimo de los proyectiles 1-2 de Alcalá la Vieja. Obra derivada de OrtoPNOA 2014 CC-BY scne.es. Fotografía: Mario Ramírez Galán. 


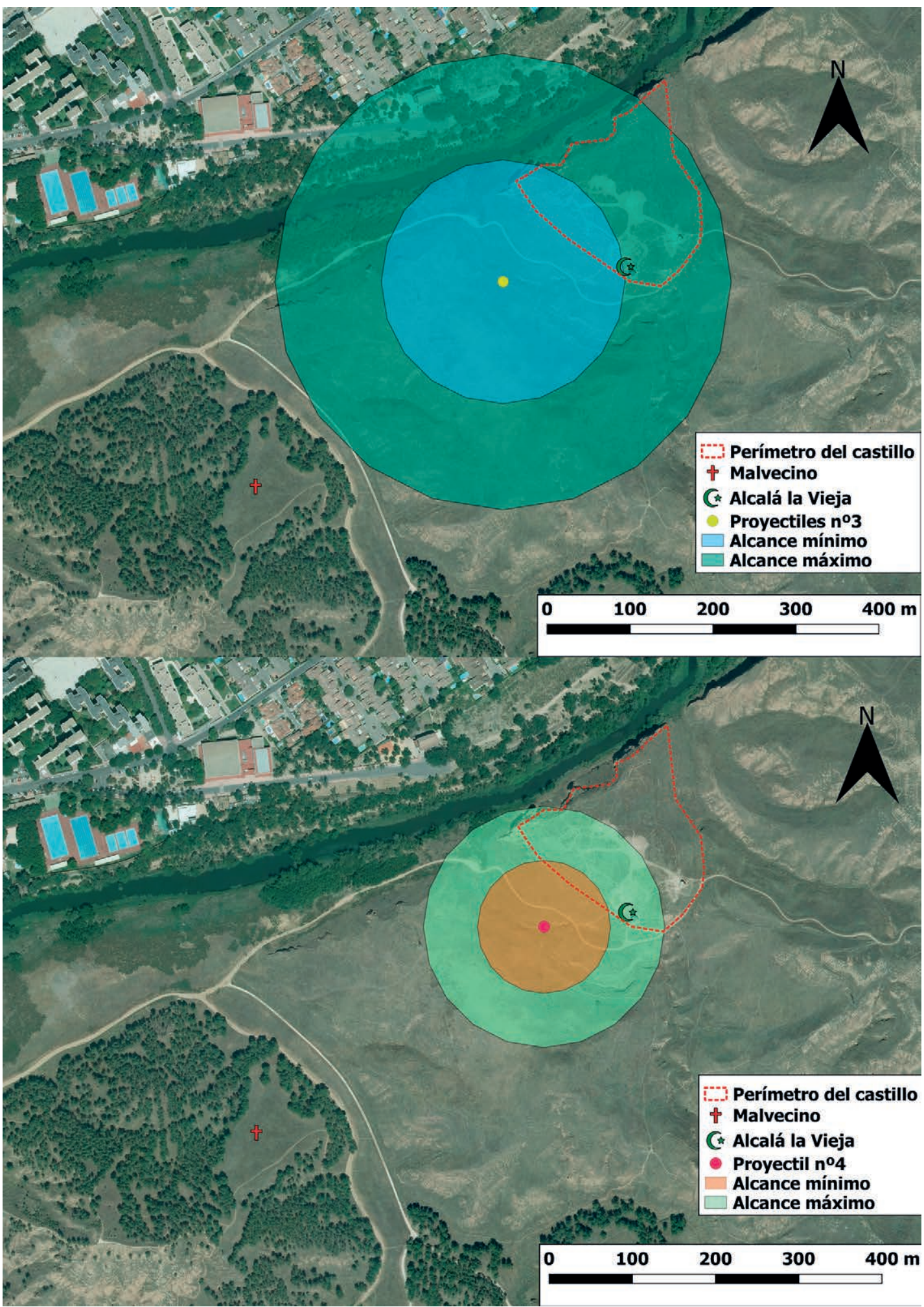

Figura 7. Alcance máximo y mínimo de los proyectiles 3-4 de Alcalá la Vieja. Obra derivada de OrtoPNOA 2014 CC-BY scne.es. Fotografía: Mario Ramírez Galán. 
- Longitud del brazo del trabuco.

- Peso medio del contrapeso.

Ante esta situación, se optó por el uso de series de estimaciones con varios valores para así obtener una serie de resultados a través de los cuales poder establecer un rango. Tras la aplicación de dichas estimaciones obtuvimos una serie de valores, los cuales corresponderían al radio de una circunferencia, y posteriormente seleccionamos el valor máximo y mínimo para cada proyectil.

Una vez obtenidos los radios para cada bolaño, fue necesario la utilización de un software de sistemas de información geográfica (SIG) para la obtención de áreas de influencia y así poder observar las zonas cubiertas por dichas áreas, localizando las ubicaciones con mayor potencialidad para haber sido usadas como zonas de despliegue de los trebuchets.

El programa utilizado generó dos áreas de influencia para cada caso y lo más interesante fue que ninguna de ellas incluía el cerro de Malvecino, lugar donde todas las fuentes documentales mencionaban como el enclave donde el arzobispo de Toledo desplegó los trabucos. Esta información corrobora lo que indicábamos con anterioridad, y es que la distancia entre el Malvecino y Alcalá la Vieja era inabarcable para ninguna máquina en ese momento de la historia.

Los buffers (término anglosajón para área de influencia) cubrían distintos emplazamiento en los alrededores del castillo, varios de los cuales fueron descartados automáticamente, bien porque ocupaban puntos a nivel del pie de las elevaciones o bien porque se encontraban en lugares peligrosos y que podían haber sido atacados con facilidad por las tropas musulmanas. A pesar de ello, uno de esos emplazamientos contaba con una serie de rasgos que lo hacían perfecto para dicha función, como fue la zona de Los Catalanes.

Los Catalanes es una elevación que se encuentra situada entre el puesto cristiano en Malvecino y la fortaleza de Alcalá la Vieja, dotándola de un claro valor estratégico para los intereses del ejército atacante. Posee una altura superior al lugar donde se emplazaba el castillo árabe, lo cual le pudo permitir un mejor control visual y también un mejor ángulo de disparo. Esta elevación orográfica, se encuentra protegida por varias defensas naturales en distintas zonas, facilitando la defensa ante un posible contrataque. A esto hay que añadir que estamos

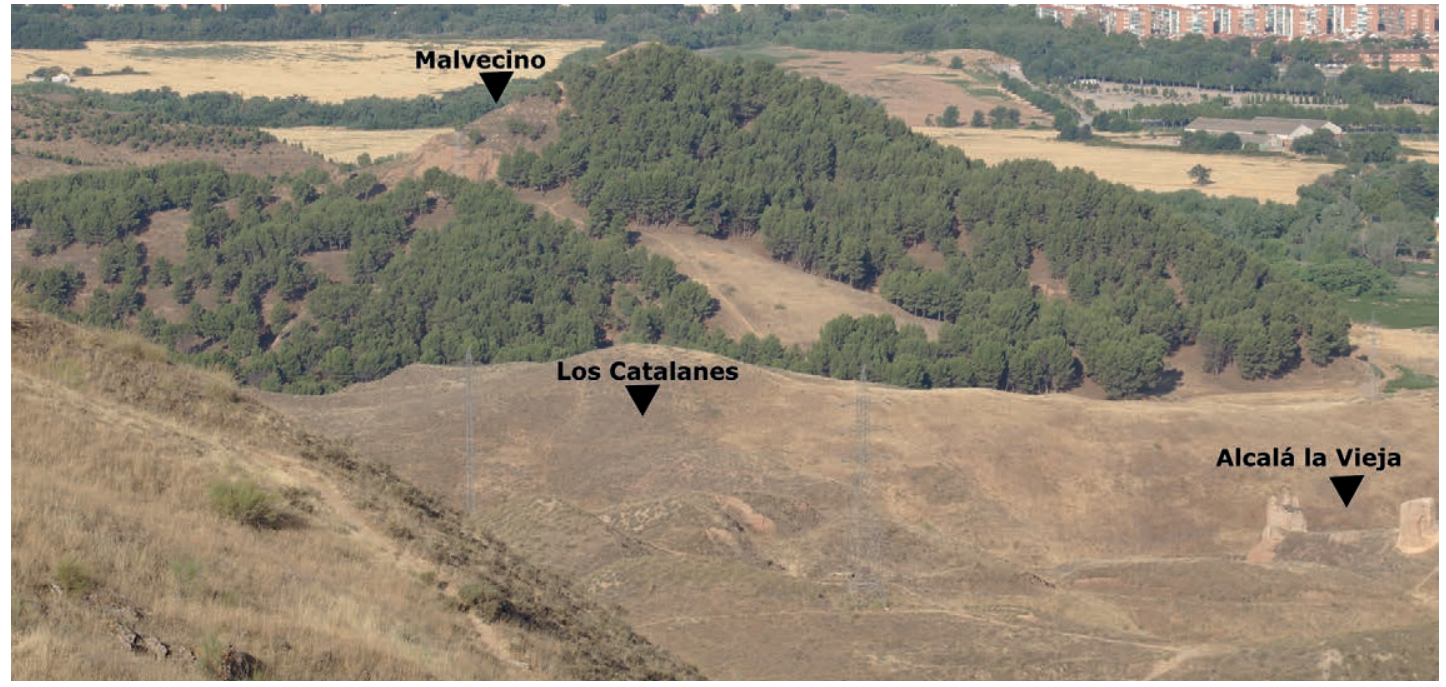

Figura 8. Entorno del yacimiento donde se observan las localizaciones de Malvecino, Los Catalanes y Alcalá la Vieja. Fotografía: Mario Ramírez Galán. 
hablando de una zona plana prácticamente en su totalidad, lo cual influiría positivamente a la hora de disparar dichas máquinas de guerra, puesto que evitaría cualquier posible inestabilidad de la máquina durante el disparo, dándole mayor efectividad y fiabilidad.

\section{CONCLUSIONES}

Con la realización de este trabajo ha sido posible aportar un nuevo enfoque sobre el asedio del castillo de Alcalá de la Vieja gracias a la utilización de un estudio interdisciplinar, combinando la información histórica y arqueológica con el empleo de métodos provenientes de otros campos de estudio, como son la física y los estudios espaciales.

Gracias a los datos obtenidos hemos podido ver como la idea tradicional que se ha venido utilizando durante años a la hora de estudiar dicho conflicto bélico carecía de validez, debido en gran parte a la falta de información sobre determinados aspectos. Las fuentes históricas que trataban este hecho eran todas de carácter secundario, provocando un vacío documental por la inexistencia de documentos contemporáneos al asedio. Como consecuencia de ello, los sucesivos autores pudieron reproducir los mismos errores al no contar con otras interpretaciones para poder corroborar las descripciones. Todo ello se ha venido arrastrando hasta ahora, lo cual había imposibilitado tener un conocimiento correcto sobre el asalto a Alcalá la Vieja.

Los valores obtenidos mediante el estudio físico del proceso de lanzamiento de los proyectiles de piedra ha posibilitado solventar algunos de estos vacíos documentales, puesto que se han aportado valores que se basan en cálculos reales.

El estudio espacial del entorno era necesario para poder obtener una visualización gráfica de las posibles zonas donde se pudieron localizar los trabucos, los cuales no estarían fijados en la posición defendida tradicionalmente sino que pudieron localizarse emplazados en la elevación de Los Catalanes, la cual posee ciertos rasgos que refuerzan esta teoría.

La propuesta de esta nueva zona, como posible emplazamiento, da un giro a la interpretación que se ha venido haciendo del asedio, siendo el punto de partida para futuros trabajos.

\section{AGRADECIMIENTOS}

Queremos agradecer al Museo Arqueológico Regional de la Comunidad de Madrid, y en especial a Miguel Contreras, la posibilidad de estudiar los proyectiles de piedra y su ayuda durante el proceso. Agradecemos a María Benítez Galán la realización de los cálculos físicos y a Roberto Sardinero Navarro por la ayuda prestada.

\section{BIBLIOGRAFÍA}

Basista, M. (2007): «Hybrid or Counterpoise? A Study of Transitional Trebuchets». Journal of Medieval Military History, V: 33-55. https://doi.org/10.1017/upo9781846155604.003

Boas, A. J. (2017a): «Archaeological evidence for the Mamluk sieges and dismantling of Montfort: a preliminary discussion», A. J. Boas y R. G. Khamisy (eds.), Montfort. Hisory, early research and recent studies of the principal fortress of the Teutonic Order. Leiden / Boston, Brill: 42-55.

Boas, A. J. (2017b): «Stone, metal, wood and worked bone finds from the 1926 expedition», A. J. Boas y R. G. Khamisy (eds.), Montfort. Hisory, early research and recent studies of the principal fortress of the Teutonic Order. Leiden / Boston, Brill: 195-220.

Bru Castro, M. Á. y Schnell Quiertant, P. (2014): «Reflexionando sobre los orígenes andalusíes de la Atalaya de Torrelodones», Actas de las décimas jornadas de patrimonio arqueológico en la Comu- 
nidad de Madrid, Alcalá de Henares, 2013. Madrid, Dirección General de Patrimonio Histórico, Comunidad de Madrid: 93-104.

Calleja Carrasco, J. D. (1897): Alcalá La Vieja, ensayo histórico o apuntes para una monografía de aquel castillo. Guadalajara, Imprenta de la Diputación Provincial.

Castro Priego, M. (2011): La problemática del registro Arqueológico de Alcalá de Henares. Tesis doctoral, Universidad de Alcalá de Henares. http://hdl.handle.net/10017/18541

Chevedden, P. E. (1998): «The hybrid trebuchet: the halfway step to the counterweight trebuchet», D. J. Kagay y T. M. Vann (eds.), On the Social Origins of Medieval Institutions, Essays in Honor of Joseph F. O'Callaghan. Leiden / Boston / York / Köln, Brill: 179-222.

Chevedden, P. E. (2000): «The Invention of the Counterweight Trebuchet: A Study in Cultural Diffusion». Dumbarton Oaks Papers, 54: 71-116. https://doi.org/10.2307/1291833

Chevedden, P. E., Eigenbrod, L., Foley, V. y Soedel, W. (1995): «The trebuchet». Scientific American, 273 (1): 66-71. https://doi.org/10.1038/scientificamerican0795-66

Chevedden, P. E., Shiller, Z., Samuel, R., Kagay, D. J. y Gilbert, S. R. (2000): «The traction trebuchet: a triumph of four civilizations». Viator, 31: 433-486. https://doi.org/10.1484/j.viator.2.300774

Echevarría Arsuaga, A. (1990): «Los castillos de Alcalá la Vieja y Santorcaz en la frontera cristianomusulmana española», Congreso de historiadores y geógrafos: actas I [celebrado en la Facultad de Geografia e Historia de la Universidad Complutense de Madrid del 12 al 16 de diciembre de 1988. Madrid, Editorial de la Universidad Complutense: vol. 1, 631-642.

Fernández-Galiano, D. y Garcés-Toledano, A. (1978): «Problemática y estado actual de los yacimientos arqueológicos en el corredor Madrid-Guadalajara». Wad-al-Hayara: Revista de estudios de Guadalajara, 5: 7-34.

Fita Colomé, F. (1885): «Bula inédita de Honorio II». Boletín de la Real Academia de la Historia, VII: 336-346.

Fulton, M. S. (2019): «The siege of Montfort and Mamluk artillery technology in 1271: integrating the archaeology and topography with the narrative sources». Journal of military history, 3 (3): 689-717.

García Fitz, F. (1998): Castilla y León frente al islam. Estrategias de expansión y tácticas militares (siglos XI-XIII). Sevilla, Secretariado de publicaciones de la Universidad de Sevilla.

García Fitz, F. (2005): «¿Machinis validas? Tipología y funcionalidad de las máquinas de asedio del medievo hispano. Castilla-León, siglo XI al XIII», A. Ruibal Rodríguez (coord.), Actas del III congreso de castellología ibérica, Guadalajara, 28 de octubre - 1 de noviembre de 2005. Guadalajara, Diputación Provincial de Guadalajara: 219-254.

García Fitz, F. (2011): «Tecnología, literatura técnica y diseño de máquinas de guerra durante la Baja Edad Media occidental. El Thexaurus regis Franciae acquisitionibus Terrae Santae de Guido da Vigevano (1335)». Anuario de estudios medievales, 41 (2): 819-864. https://doi.org/10.3989/ aem.2011.v41.i2.373

Gillmor, C. (1981): «The introduction of the traction trebuchet into the Latin West». Viator, 12: 1-8. https://doi.org/10.1484/j.viator.2.301479

Herrera Casado, A. (1985): «La Marca Media de Al-Andalus en tierras de Guadalajara». Wad-al-Hayara: Revista de estudios de Guadalajara, 12: 9-26.

Hosler, J. D. (2015): «Identifying King Stephen's artillery». Journal of Conflict Archaeology, 10 (3): 192-203. https://doi.org/10.1080/15740773.2016.1181857

Jiménez de Rada, R. (1989): Historia de los Hechos de España. Introducción, traducción, notas e índices de Juan Fernández Valverde. Madrid, Alianza.

López Marcos, M. Á., Presas Vías, M. M., Serrano Herrero, E. y Torra Pérez, M. (2011): «Excavaciones y conservación preventiva en la fortaleza de Alcalá la Vieja (Alcalá de Henares, Madrid)», Actas de las octavas jornadas de patrimonio arqueológico de la Comunidad de Madrid, 2011. Madrid, Boletín Oficial de la Comunidad de Madrid: 235-246

López Marcos, M. Á., Presas Vías, M. M., Serrano Herrero, E. y Torra Pérez, M. (2013): «La fortaleza de Qal'at 'Abd as-Salam. La recuperación de una dignidad perdida (Alcalá de Henares, Madrid)». Arqueología de la Arquitectura, 10: 1-19. https://doi.org/10.3989/arq.arqt.2013.017

Morales, A. de (1793): Opúsculos castellanos. Madrid, Benito Cano.

Palacios Ontalva, J. S. (2006): «Castillos contra castillos. Padrastros y fortalezas de asedio en la España Medieval». Arqueología y territorio medieval, 13 (2): 33-55. https://doi.org/10.17561/aytm. v13i2.1511 
Portilla y Esquivel, M. (1725). Historia de la Ciudad de Compluto. Alcalá de Henares: por Joseph Esportosa, Impresor de la Universidad.

Raphael, K. y Tepper, Y. (2005): «The Archaeological Evidence from the Mamluk Siege of Arsuf». Mamluk Studies Review 9: 85-100.

Ramírez Galán, M. (2016): «El entendimiento de las técnicas bélicas medievales a través de los restos arqueológicos», C. Tejedor, F. J. Pascual, G. Ros, A. Guerrero, J. Aguado y M. Á. Hidalgo (eds.), Quintas Jornadas de Jóvenes Investigadores de la Universidad de Alcalá: Humanidades y Ciencias Sociales. Alcalá de Henares, Servicio de Publicaciones Universidad de Alcalá: 119-126.

Ramírez Galán, M. (2017): Los yacimientos olvidados: registro y musealización de campos de batalla. Oxford, Archaeopress.

Ramírez Galán, M. y Montalvo Laguna, R. (2018): «Reinterpretando el campo de batalla de Alcalá la Vieja», M. Alcántara, M. García Montero y F. Sánchez López (coords.), Memoria del $56^{\circ}$ Congreso Internacional de Americanistas. Salamanca, Ediciones Universidad de Salamanca: 172-186.

Ramírez Galán, M., Montalvo Laguna, R. y Benítez Galán, M. (2019): «The battle of Alcalá la Vieja. Location and understanding of a medieval battle», N. Moreira, M. Derderian y A. Bissonnette (eds.), Fields of Conflict. Conference proceedings Vol. 3. $10^{\text {th }}$ Biennial International Conference, 23-60 September 2018, Mashantucket Pequot Museum \& Research Center: 23-43.

Sáez Abad, R. (2007): Artillería y poliorcética en la Edad Media. Madrid, Almena.

Saimre, T. (2006): «Trebuchet-A gravity-operated siege engine». Estonian Journal of Archaeology, 10: 61-80.

Tarver, W. T. S. (1995): «The Traction Trebuchet: A Reconstruction of an Early Medieval Siege Engine». Technology and Culture, 36 (1): 136-167. https://doi.org/10.2307/3106344

Torres Balbás, L. (1959): «Complutum, Qal'at 'Abd al-Salam y Alcalá de Henares». Boletín de la Real Academia de la Historia, CXLIV: 155-188.

Tsurtsumia, M. (2015): «Medieval Georgian Poliorcetica». Historia I ŚWIAT, 4: 175-204.

Turina Gómez, A. (1990): «El castillo de Alcalá de Henares», Madrid del s. IX al XI: Madrid, octubrenoviembre 1990, Real Academia de Bellas Artes de San Fernando. Madrid, Comunidad de Madrid: 189-194

Zozaya Stabel-Hansen, J. (1983): «Excavaciones en la fortaleza de Qal'at 'Abd-al-Salam (Alcalá de Henares, Madrid)». Noticiario Arqueológico Hispánico, 17: 411-529.

Recibido: 02-12-2019

Aceptado: 03-06-2020 